\title{
Scrophulariae Radix Aqueous Extracts Ameliorate the Pressure Overloaded Heart Failure by Transverse Aortic Constriction in Mice
}

\author{
Seong-jin Woo, Kyung-min Baek, Woo-seok Jang \\ Dept. of Cardiovascular and Neurologic Diseases of Korean Internal Medicine, \\ Daegu Oriental Hospital of Daegu Haany University
}

\section{Scrophulariae Radix Aqueous Extracts Ameliorate the Pressure Overloaded Heart Failure by Transverse Aortic Constriction in Mice}

\author{
Seong-jin Woo, Kyung-min Baek, Woo-seok Jang \\ Dept. of Cardiovascular and Neurologic Diseases of Korean Internal Medicine, \\ Daegu Oriental Hospital of Daegu Haany University
}

\begin{abstract}
Objectives: The purpose of this study was to investigate the cardioprotective effect of the potent antioxidant properties of Scrophulariae Radix (SR) aqueous extracts by examining pressure overload (PO) heart failure (HF) induced by transverse aortic constriction (TAC) of C57BL/6 mice.

Methods: SR (500, 250, $125 \mathrm{mg} / \mathrm{kg})$ and resveratrol $(10 \mathrm{mg} / \mathrm{kg})$ were administered orally once a day for 14 days, after the TAC operation. Changes in mortality, the body and heart weights, histopathology of the heart, and antioxidant defense system of the heart were analyzed.

Results: After the TAC operation, increases were observed in mortality, heart weights, left ventricular hypertrophy, and lytic and focal fibrotic histological change, and destruction of the heart antioxidant defense system. However, the HF signs showed dose-dependent inhibition following 14 days of continuous oral treatment with SR. A SR dose of $125 \mathrm{mg} / \mathrm{kg}$ gave a similar inhibition to that obtained with resveratrol at $10 \mathrm{mg} / \mathrm{kg}$.

Conclusions: Oral administration of SR beneficially improves PO-induced HF following TAC surgery by increasing the activity of the heart antioxidant defense system. The overall effect of SR at $125 \mathrm{mg} / \mathrm{kg}$ is similar to the effect of resveratrol at $10 \mathrm{mg} / \mathrm{kg}$. However, more detailed mechanistic studies should be performed by screening of the biologically active compounds in SR.
\end{abstract}

Key words: Scrophulariae Radix, heart failure, cardioprotective, transverse aortic constriction, in vivo

· 투고일 : 2018.09.03, 심사일: 2018.09.27, 게재확정일: 2018.10.01

- Corresponding author: Woo-seok Jang Dept. of Cardiovascular and Neurologic Diseases of Korean Internal Medicine, Daegu Oriental Hospital of Daegu Haany University, 136 Sinchendong-ro, Suseong-gu, Daegu, Republic of Korea TEL: 053-770-2125 FAX: 053-770-2055 E-mail: freesoso1@naver.com

- 이 논문은 2017년도 대구한의대학교 대학원 한의학 석사학위 논문임.

\section{Introduction}

Heart failure ( $\mathrm{HF}$ ) is a pathological condition in which the heart fails to function efficiently and does not supply blood and oxygen to maintain life ${ }^{1}$. HF is induced by left ventricular hypertrophy caused by pressure overload $(\mathrm{PO})^{2}$. 
Endogenous antioxidant defense system controls the amount of reactive oxygen species (ROS) to persist physiological homeostasis. However, when various cardiovascular diseases including $\mathrm{HF}$ are present ROS production predominates over antioxidant defense system, causing chronic oxidative stress and damaging cells ${ }^{2.3}$. Therefore, it is necessary to find alternate strategies to provide safe and effective HF therapy through natural antioxidative agents ${ }^{2.4}$.

Resveratrol (trans-3,4,5-trihydroxystilbene), a polyphenol found mainly in grapes and berries, have been studied in a variety of experimental environments, including hypertension, myocardial infarction, and $\mathrm{HF}^{5,6}$. In particular, recent study have examined the effect of resveratrol on the prevention of chronic pathological changes in cardiac function and structure of PO-induced $\mathrm{HF}$ in mice ${ }^{2}$.

Scrophulariae Radix (SR), a dried root of Scrophularia buergeriana Miquel has been used for a long time with excellent traditional therapeutic effects on yin nourishing, blood cooling, fire purging and toxin removal ${ }^{7}$. Recent pharmacological research and clinical practice explained that it possesses anti-inflammatory ${ }^{8}$, antimicrobial ${ }^{9}$ activities, and anti-angiogenesis ${ }^{10}$. So it can be used for the treatment of pharyngalgia, constipation, rheumatism, arthritis and conjunctival congestion ${ }^{11}$. Especially SR has potent antioxidant-based cardioprotective effects against coronary artery ligation-induced ventricular remodeling rat models ${ }^{12,13}$.

However, no study has examined the effects of SR in preventing chronic pathological changes on the cardiac structure and function on PO-induced HF in mice. Therefore, the aim of this study is to observe the cardioprotective effect of SR on
PO-induced HF in mice through possible antioxidant effects.

\section{Materials and methods}

\section{Animals and husbandry}

A total of Sixty-six healthy male SPF/VAF inbred C57BL/6 mice (Seungnam, Korea; OrientBio; 6-week old; body weight 18-21 g), were used for 7 days after acclimatization. Six groups, total 40 TAC operated or eight sham mice were selected on the basis of body weight at 14 days after TAC surgery (Table 1, Fig. 1).

2. Preparations and administration of test materials

SR produced in Andong (Korea), were purchased from local herb store (Omniherb, Yeoungcheon, Korea) under the inspection of herbologist (Prof. Park JH, KMD, PhD). Both resveratrol and SR are dissolved (up to $1 \mathrm{mg} / \mathrm{mL}$ solution in resveratrol and up to $50 \mathrm{mg} / \mathrm{mL}$ solution in SR) in distilled water. SR for a dose of 50,25 and $12.5 \mathrm{mg} / \mathrm{kg}$ concentration by which directly dissolved in $1 \mathrm{~mL}$ of distilled water and then orally administered in a dose of $10 \mathrm{~mL} / \mathrm{kg}$ at 500,250 and $125 \mathrm{mg} / \mathrm{kg}$ equivalent using gastric gavages, once per day for 14 day from 14 day after TAC surgery. Resveratrol also has been dissolved in distilled water at concentration of $1 \mathrm{mg} / \mathrm{mL}$ and orally administered at a dose of $10 \mathrm{~mL} / \mathrm{kg}$ as equivalence to $10 \mathrm{mg} / \mathrm{kg}$. In TAC control and sham mice, the equal amount of distilled water was orally administered, once per day for 14 day from 14 day after TAC surgery, respectively (Table 1, Fig. 1). 
Table 1. Experimental Design

\begin{tabular}{cccc}
\hline Groups & Surgery & Group identification & Treatment \\
\hline Control & Sham & Sham control & Distilled water $10 \mathrm{~mL} / \mathrm{kg} /$ day \\
Control & TAC & TAC control & Distilled water $10 \mathrm{~mL} / \mathrm{kg} /$ day \\
Reference & TAC & Resveratrol & Resveratrol $10 \mathrm{mg} / \mathrm{kg} /$ day \\
Active & TAC & SR 500 & SR $500 \mathrm{mg} / \mathrm{kg} /$ day \\
Active & TAC & SR 250 & SR $250 \mathrm{mg} / \mathrm{kg} /$ day \\
Active & TAC & SR 125 & SR $125 \mathrm{mg} / \mathrm{kg} /$ day \\
\hline
\end{tabular}

SR : Scrophulariae Radix aqueous extracts, TAC : transverse aortic constriction

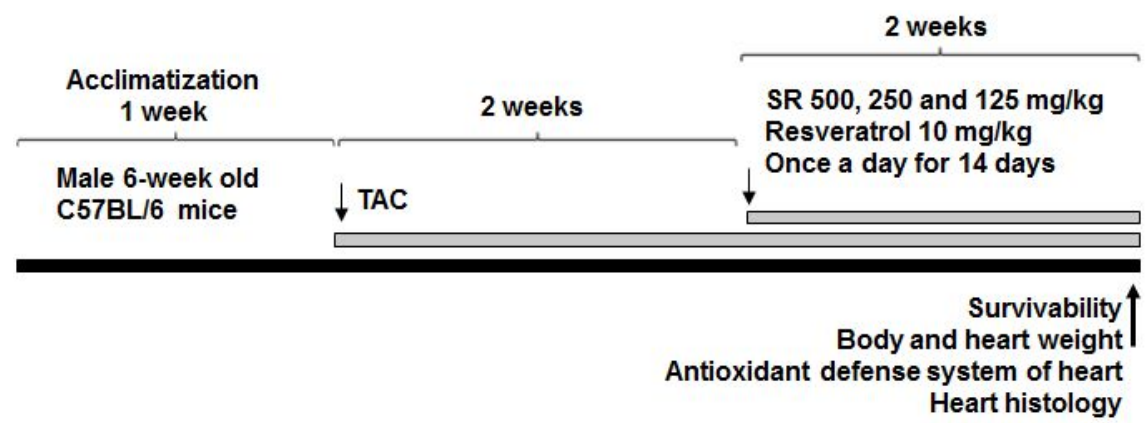

Fig. 1. Experimental design.

SR : Scrophulariae Radix aqueous extracts, TAC : transverse aortic constriction

\section{TAC operation}

The central thoracotomy was made with a length of $3 \mathrm{mM}$. The transverse aortic arch was connected (7-0 Prolene) with an overlying 28-gauge needle between left common carotid and the innominate arteries, and then the needle was removed to leave a discrete region of stenosis. A chest was closed, and then pneumothorax was evacuated.

\section{Mortalities}

Any unusual mortalities were recorded before and after the administration at least twice a day from day of first administration to last drug treatment day.
5. Body weight measurements

The body weight change was measured on 1 day before the initial test article administration, the day of the first test material administration, 1, 7, 13, 14 days after initial resveratrol or SR administration using an automatic electronic scales (Precisa Instrument, Dietikon, Switzland).

\section{Heart weight measurements}

At sacrifice, the heart weights of all survived animals were assessed at $\mathrm{g}$ levels, and to reduce the difference between individual weight, the relative body weight ( $\%$ of body weight) was calculated using sacrifice body weight and absolute heart weight. 
7. Analysis of heart antioxidant defence system

Some of the heart from survived animals at sacrifice (5 mice in each group) were homogenized and weighed with a buffer consisting of $10 \mathrm{mM}$ Tris- $\mathrm{HCl}$, and 0.1 M MEDTA (pH 7.4), $10 \mathrm{mM}$ sucrose and then centrifugated, for $15 \mathrm{~min}$ at $12,000 \mathrm{~g}$.

1) Analysis of lipid peroxidation

In order to quantify the amount of lipid peroxidation, thiobarbituric acid reactive substances (TBARS) produced during the acid-heating reaction was measured. Therefore samples of tissue homogenate were mixed with trichloroacetic acid $(10 \% ; 1 \mathrm{~mL}$, Merck, San Francisco, CA, USA) and thiobarbituric acid (0.67\%; 1mL, Merck, San Francisco, CA, USA) before heating in a boiling water bath (15 min). The TBARS absorbance was measured at an optical density (OD) of $535 \mathrm{nM}$, using a UV/VIS spectrophotometer (Mecasys, Daejeon, Korea, OPTIZEN POP) and the results were expressed as MDA equivalents $(\mathrm{nM} / \mathrm{g})$.

2) Analysis of CAT and SOD activity

The level of CAT activity was measured by the decrease in the hydrogen peroxide OD at $240 \mathrm{nM}$, using UV/VIS spectrophotometer (Mecasys, Daejeon, Korea, OPTIZEN POP). CAT activity is determined by the amount of enzyme required to degrade 1 $n M$ of $\mathrm{H}_{2} \mathrm{O}_{2}$ per minute, at $25{ }^{\circ} \mathrm{C}$ and $\mathrm{pH}$ 7.8. SOD activity levels were measured from adrenaline autoxidation inhibition. The SOD activity was measured by the inhibition degree of the reaction at OD $560 \mathrm{nM}$. One unit of SOD enzyme activity is determined by enzyme that decrease the initial absorbance of adrenaline by $50 \%$ using a UV/VIS spectrophotometer (Mecasys, Daejeon, Korea, OPTIZEN POP) for $1 \mathrm{~min}$.

3) Analysis of GSH levels
The total GSH levels of the reduced and disulphide type tissue homogenate samples were evaluated. GSH reduction is recirculated to glutathione reductase and NADPH, associated with an absorption change at $412 \mathrm{nM}$ (associated with a decrease in DTNB). This analysis has been modified for use with microplate readers (Tecan, Männedorf, Switzerland).

\section{Histological process}

At the sacrifice, each of the myocardial regions collected from the surviving animals (5 mice per group). To better observe changes, mean numbers of lytic necrotic myocardial fibers (myofibers/1000 myofibers), total left ventricle thickness from endocardium to pericardium ( $\mu \mathrm{M} /$ heart) and myocardical diameters ( $\mu \mathrm{M} /$ fiber) were measured by histomorphometrical analysis using computer assisted image analysis program (Quebec, Canada, iSolution FL ver 9.1, IMT $i$-solution Inc.) under $\mathrm{H} \& \mathrm{E}$ stain with mean percentages of interstitial and perivascular collagen fiber occupied areas in left ventricle $\left(\% / \mathrm{mm}^{2}\right)$ under Sirius red stain 2 .

\section{Statistical analysis}

All data are described as mean \pm standard deviation (SD). Multiple comparison tests were performed for different dose groups. Variance homogeneity was investigated using the Levene test. If the Levene test does not show significant deviations from variance homogeneity, data were analyzed by one-way analysis (ANOVA) test and least significant difference (LSD) test to determine which group pair was significantly different.

Kruskal-Wallis H test, Non-parametric comparison test were performed when the dispersion homogeneity was significantly out of the Levene test. When significant difference were observed in a Mann-Whitney 
$\mathrm{U}$ (MW) test, the Kruskal-Wallis $\mathrm{H}$ test was performed to determine a particular pair of group comparisons, which is very different. Statistical analysis was performed using SPSS for Windows (Armonk, NY, USA, Release 14.0K, IBM SPSS Inc.).

\section{Results}

\section{Survivability}

Survivability after 14 days of experiment in sham control was $100.0 \%$, and they were detected as $62.5,75.0,100.0,87.5$ and $75.0 \%$ in TAC control, resveratrol $10 \mathrm{mg} / \mathrm{kg}$, SR 500, 250, $125 \mathrm{mg} / \mathrm{kg}$ treated mice, respectively (Table 2).

\section{Changes on the body weight}

Significant changes of body weight during 14 days were not detected in all TAC operated mice as compared to sham control. In addition no significant change of body weight was detected in all three different doses of SR or resveratrol $10 \mathrm{mg} / \mathrm{kg}$ treated mice as compared to TAC control (Table 3).

Table 2. Mortalities Observed in Sham or TAC Operated Mice

\begin{tabular}{|c|c|c|c|c|c|c|c|c|c|c|c|c|c|c|c|c|}
\hline \multirow{2}{*}{ Groups Time } & \multicolumn{14}{|c|}{ Days of administration } & \multirow{2}{*}{ Total ${ }^{*}$} & \multirow{2}{*}{ Survival (\% } \\
\hline & 0 & 1 & 2 & 3 & 4 & 5 & 6 & 7 & 8 & 9 & 10 & 11 & 12 & 13 & & \\
\hline Sham control & 0 & 0 & 0 & 0 & 0 & 0 & 0 & 0 & 0 & 0 & 0 & 0 & 0 & 0 & $0 / 8$ & 100.00 \\
\hline TAC control & 0 & 0 & 0 & 0 & 1 & 0 & 0 & 2 & 0 & 0 & 0 & 0 & 0 & 0 & $3 / 8$ & 62.50 \\
\hline Resveratrol & 0 & 0 & 0 & 0 & 1 & 0 & 0 & 0 & 0 & 1 & 0 & 0 & 0 & 0 & $2 / 8$ & 75.00 \\
\hline SR 500 & 0 & 0 & 0 & 0 & 0 & 0 & 0 & 0 & 0 & 0 & 0 & 0 & 0 & 0 & $0 / 8$ & 100.00 \\
\hline SR 250 & 0 & 0 & 0 & 0 & 0 & 0 & 0 & 1 & 0 & 0 & 0 & 0 & 0 & 0 & $1 / 8$ & 87.50 \\
\hline SR 125 & 0 & 0 & 0 & 0 & 0 & 0 & 0 & 0 & 1 & 1 & 0 & 0 & 0 & 0 & $2 / 8$ & 75.00 \\
\hline
\end{tabular}

The values are expressed as the number of died animals.

* Total mortality for 14 days of observation - died animals/whole animal observed (eight mice in each group).

SR : Scrophulariae Radix aqueous extracts, TAC : transverse aortic constriction

Table 3. Body Weight Gains Observed in Sham or TAC Operated Mice

\begin{tabular}{cccc} 
& Times & \multicolumn{2}{c}{ Body weights at } \\
\cline { 2 - 4 } Groups & First administration [A] & Sacrifice [B] & Weight gains [B-A] \\
\hline Sham control & $18.40 \pm 1.52$ & $21.23 \pm 1.53$ & $2.83 \pm 0.43$ \\
TAC control & $18.24 \pm 1.29$ & $20.20 \pm 1.05$ & $2.50 \pm 0.37$ \\
Resveratrol & $18.31 \pm 1.51$ & $21.17 \pm 1.70$ & $2.68 \pm 0.52$ \\
SR 500 & $18.28 \pm 1.56$ & $20.74 \pm 1.62$ & $2.46 \pm 0.51$ \\
SR 250 & $18.23 \pm 1.43$ & $20.59 \pm 1.44$ & $2.49 \pm 0.49$ \\
SR 125 & $18.26 \pm 1.28$ & $20.82 \pm 1.66$ & $2.72 \pm 0.44$ \\
\hline
\end{tabular}

Values are expressed as Mean \pm S.D. of a variable number of mice according to mortality (see Table 2), g.

SR : Scrophulariae Radix aqueous extracts, TAC : transverse aortic constriction 


\section{Changes on the heart weight}

After the administration of 14 days, a significant increases $(p<0.01)$ in the absolute and relative heart weights in TAC control as compared to sham control has been demonstrated. However, heart hypertrophic changes induced by TAC were dramatically inhibited by treatment of SR $500,250,125 \mathrm{mg} / \mathrm{kg}$, dose-dependently, and also by resveratrol $10 \mathrm{mg} / \mathrm{kg}$ as compared to TAC control; significant $(p<0.01)$ and dose-dependent reduction of absolute and relative weight of the heart were noticed in all three different dose of SR administered mice, and also in resveratrol $10 \mathrm{mg} / \mathrm{kg}$ treated mice as compared to TAC control (Fig. 2, 3).

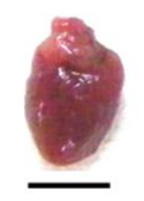

$-\mathbf{A}-$

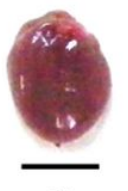

-D-

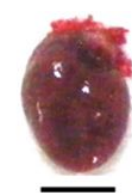

-B-

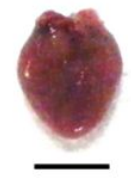

$-\mathbf{E}$
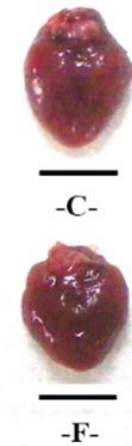

Fig. 2. The representative gross images of heart, taken from sham or TAC operated mice.

A : sham control, B : TAC control, C : resveratrol, D : SR 500, E : SR 250, F : SR 125, Scale bars : $5 \mathrm{mM}$

SR : Scrophulariae Radix aqueous extracts, TAC : transverse aortic constriction

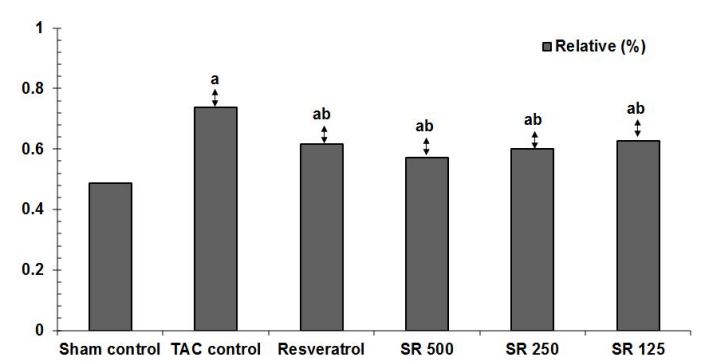

Fig. 3. Changes on the heart weights in sham or
TAC operated mice.

Values are expressed as Mean \pm S.D. of a variable number of mice according to mortality (see Table 2), g.

SR : Scrophulariae Radix aqueous extracts, TAC : transverse aortic constriction

a $p<0.01$ as compared to sham control by LSD test

${ }^{\mathrm{b}} p<0.01$ as compared to TAC control by LSD test

4. Effects on the heart antioxidant defense system

1) Changes on the heart MDA levels

In the TAC control, a significant $(p<0.01)$ increase in heart lipid peroxidation and a rise in MDA level were observed compared to sham control. However, the elevation of MDA levels was significantly reduced in a dose-dependent manner in all three different dose of SR. In addition, the heart lipid peroxidation in resveratrol $10 \mathrm{mg} / \mathrm{kg}$ treated mice was significantly $(p<0.01)$ reduced compared to TAC control (Table 4).

2) Changes on the heart GSH contents

Significant reduction $(p<0.01)$ of heart endogenous antioxidant, GSH content in TAC control was observed compared to sham control. However, the reduction of heart GSH content by TAC operation was significantly $(p<0.01)$ and dose-dependently inhibited during the 14 days of oral administration of SR 500, 250, $125 \mathrm{mg} / \mathrm{kg}$, respectively. In addition, heart GSH content of resverastrol $10 \mathrm{mg} / \mathrm{kg}$ treated mice were also significantly $(p<0.01)$ increased as compared to TAC control (Table 4).

3) Changes on the heart CAT activity

Significant reduction $(p<0.01)$ of the CAT activity, heart endogenous antioxidative enzyme was detected in TAC control as compared to sham control. However, the reduction of heart CAT activitiy was significantly $(p<0.01)$ and dose-dependently inhibited during the 14 days of oral administration of SR 500, 250, $125 \mathrm{mg} / \mathrm{kg}$, respectively. In addition, 
the heart CAT activities in resveratrol $10 \mathrm{mg} / \mathrm{kg}$ treated mice were also significantly $(p<0.01)$ increased as compared to TAC control (Table 4).

4) Changes on the heart SOD activity

Significant $(p<0.01)$ reduction of the SOD activities, heart endogenous antioxidative enzyme in TAC control was observed compared to sham control. But dramatic significant $(p<0.01)$ increases of SOD activities were observed in resveratrol $10 \mathrm{mg} / \mathrm{kg}$, SR 500, 250, $125 \mathrm{mg} / \mathrm{kg}$ administrated mice as compared to TAC control, respectively (Table 4).

Table 4. Heart Antioxidant Defense Systems Detected in Sham or TAC Operated Mice

\begin{tabular}{|c|c|c|c|c|}
\hline Groups Items (Unit) & $\begin{array}{c}\text { MD A } \\
\text { (nM/g protein) }\end{array}$ & $\begin{array}{c}\text { GSH } \\
\text { (nM/g protein) }\end{array}$ & $\begin{array}{c}\text { CAT } \\
\text { (U/g protein) }\end{array}$ & $\begin{array}{c}\text { SOD } \\
\text { (U/g protein) }\end{array}$ \\
\hline Sham control & $0.87 \pm 0.32$ & $4.54 \pm 0.56$ & $0.79 \pm 0.13$ & $8.51 \pm 1.48$ \\
\hline TAC control & $5.04 \pm 0.74^{\mathrm{a}}$ & $0.91 \pm 0.26^{c}$ & $0.18 \pm 0.09^{a}$ & $2.29 \pm 0.61^{\mathrm{a}}$ \\
\hline Resveratrol & $2.87 \pm 0.27^{\mathrm{ab}}$ & $2.56 \pm 0.46^{\text {ce }}$ & $0.36 \pm 0.05^{\mathrm{ab}}$ & $4.06 \pm 0.57^{\mathrm{ab}}$ \\
\hline SR 500 & $1.93 \pm 0.16^{\mathrm{ab}}$ & $3.56 \pm 0.57^{\mathrm{de}}$ & $0.55 \pm 0.10^{\mathrm{ab}}$ & $5.82 \pm 0.33^{\mathrm{ab}}$ \\
\hline SR 250 & $2.04 \pm 0.15^{\mathrm{ab}}$ & $2.86 \pm 0.23^{\mathrm{ce}}$ & $0.45 \pm 0.10^{\mathrm{ab}}$ & $5.03 \pm 0.75^{\mathrm{ab}}$ \\
\hline SR 125 & $2.91 \pm 0.22^{\mathrm{ab}}$ & $2.47 \pm 0.47^{\mathrm{ce}}$ & $0.35 \pm 0.05^{\mathrm{ab}}$ & $3.99 \pm 0.69^{\mathrm{ab}}$ \\
\hline
\end{tabular}

The values are expressed as Mean \pm S.D. of 5 mice, g.

SR : Scrophulariae Radix aqueous extracts, TAC : transverse aortic constriction, MDA : Malondialdehyde, GSH : Glutathione, CAT : Catalase, SOD : Superoxide dismutase

${ }^{a} p<0.01$ as compared to sham control by LSD test

${ }^{\mathrm{b}} p<0.01$ as compared to TAC control by LSD test

${ }^{c} p<0.01$ and ${ }^{\mathrm{d}} p<0.05$ as compared to sham control by MW test

${ }^{e} p<0.01$ as compared to TAC control by MW test

\section{Effects on the heart histopathology}

1) Changes on the total thicknesses of left ventricle

In the TAC control, the total thickness of the left ventricle from endocardium to pericardium was significantly increased $(p<0.01)$ compared to sham control. However, resveratrol $10 \mathrm{mg} / \mathrm{kg}$, SR $500,250,125 \mathrm{mg} / \mathrm{kg}$ treatments significantly $(p<0.01)$ inhibited TAC-related ventricular hypertrophy compared to TAC control. In addition, SR showed clear dose-dependent effects (Table 5, Fig. 4).

2) Changes on the mean numbers of lytic necrotic cardiac muscle fibers in left ventricle

In the TAC control, the mean number of lytic necrotic cardiac muscle fibers among 1000 muscle fibers was significantly $(p<0.01)$ increased as compared to sham control. However, 14 day oral treatment with resveratrol at $10 \mathrm{mg} / \mathrm{kg}$, SR 500, 250, 125 $\mathrm{mg} / \mathrm{kg}$ in $\mathrm{TAC}$ treated mice showed a significant ( $p<0.01)$ increase in TAC-related degenerative muscle fibers as compared to TAC control, respectively. In addition, SR showed clear dose-dependent effects (Table 5, Fig. 4).

3) Changes on the diameters of cardiac muscle fibers in left ventricle

In the TAC control, the average diameter of cardiac muscle fibers was increased significantly ( $p<0.01)$ compared to the sham control. However, in TAC-operated mice, a continuous oral treatment of resveratrol $10 \mathrm{mg} / \mathrm{kg}$, SR 500, 250 and 125 
$\mathrm{mg} / \mathrm{kg}$ inhibited increases of the diameters of cardiac muscle fibers significantly $(p<0.01)$ as compared with TAC control. In addition, SR showed clear dose-dependent effects (Table 5, Fig. 5).

4) Changes on the mean percentages of perivascular collagen fiber occupied regions in left ventricle

A significant $(p<0.01)$ increase in the mean percentage of area of collagen fiber occupying area around the left ventricle was observed in TAC control. SR normalized TAC-related perivascular fibrosis in a dose-dependent and significant ( $p<0.01$ or $p\langle 0.05)$ manner. Furthermore, $10 \mathrm{mg} / \mathrm{kg}$ resveratrol is significantly reduced ( $p<0.01)$ the average percentage of area occupied by perivascular collagen fibers in the left ventricle as compared to TAC control (Table 5, Fig. 5).

5) Changes on the mean percentages of interstitial collagen fiber occupied regions in left ventricle

A significant $(p<0.01)$ increase of the mean percentage of interstitial collagen fiber in left ventricle was observed in TAC control. SR was significantly $(p<0.01$ or $p<0.05)$ related to the TAC interstitial fibrosis in a dose-dependent manner were standardized. In addition, resveratrol $10 \mathrm{mg} / \mathrm{kg}$ significantly $(p<0.01)$ reduced the mean percentage of interstitial collagen fiber occupied regions in left ventricle as compared to TAC control (Table 5, Fig. 5).

Table 5. Heart Histomorphometrical Analysis Calculated in Sham or TAC Operated Mice

\begin{tabular}{|c|c|c|c|c|c|}
\hline \multirow[b]{2}{*}{ Groups } & \multirow{2}{*}{$\begin{array}{c}\text { Total left ventricle } \\
\text { thickness } \\
\text { ( } \mathrm{M} / \text { heart })\end{array}$} & \multirow{2}{*}{$\begin{array}{l}\text { Lytic and necrotic } \\
\text { myofiber numbers } \\
\text { (fibers/1000 fibers) }\end{array}$} & \multirow{2}{*}{$\begin{array}{c}\text { Myofiber mean } \\
\text { diameters } \\
(\mu \mathrm{M} / \text { fiber })\end{array}$} & \multicolumn{2}{|c|}{$\begin{array}{c}\text { Collagen occupied regions } \\
\left(\% / \mathrm{mm}^{2}\right)\end{array}$} \\
\hline & & & & $\begin{array}{l}\text { Perivascular } \\
\text { regions }\end{array}$ & $\begin{array}{l}\text { Interstitial } \\
\text { regions }\end{array}$ \\
\hline Sham & 1197. & 53.20 & & $2.48 \pm 0.58$ & $0.96 \pm 0.32$ \\
\hline TAC contorl & $2011.33 \pm 199.81^{a}$ & $679.60 \pm 127.01^{\mathrm{a}}$ & $30.89 \pm 3.46^{\mathrm{a}}$ & $32.08 \pm 6.90^{c}$ & $26.71 \pm 3.57^{\mathrm{a}}$ \\
\hline Resveratrol & $1598.35 \pm 106.07^{\mathrm{ab}}$ & $336.60 \pm 60.76^{\mathrm{ab}}$ & $22.03 \pm 3.54^{\mathrm{ab}}$ & $7.78 \pm 1.08^{\mathrm{cd}}$ & $18.18 \pm 2.47^{\mathrm{ab}}$ \\
\hline SR 500 & $1356.30 \pm 64.57^{\mathrm{b}}$ & $169.20 \pm 34.56^{\mathrm{ab}}$ & $16.61 \pm 2.24^{b}$ & $5.39 \pm 1.18^{\mathrm{cd}}$ & $9.24 \pm 1.57^{\mathrm{ab}}$ \\
\hline SR 250 & $1508.80 \pm 85.17^{\mathrm{ab}}$ & $209.80 \pm 49.44^{\mathrm{ab}}$ & $20.33 \pm 2.31^{\mathrm{ab}}$ & $6.76 \pm 1.32^{\mathrm{cd}}$ & $15.57 \pm 3.32^{\mathrm{ab}}$ \\
\hline SR 125 & $1615.04 \pm 136.32^{a b}$ & $338.60 \pm 32.54^{a b}$ & $22.98 \pm 2.03^{\mathrm{ab}}$ & $7.95 \pm 1.65^{\mathrm{cd}}$ & $19.13 \pm 5.00^{\mathrm{ab}}$ \\
\hline
\end{tabular}

The values are expressed as Mean \pm S.D. of 5 mice, g.

SR : Scrophulariae Radix aqueous extracts, TAC : transverse aortic constriction

${ }^{a} p<0.01$ as compared to sham control by LSD test

${ }^{\mathrm{b}} p<0.01$ as compared to TAC control by LSD test

${ }^{c} p<0.01$ and ${ }^{d} p<0.05$ as compared to sham control by MW test

${ }^{e} p<0.01$ and ${ }^{\mathrm{f}} p<0.05$ as compared to TAC control by MW test 


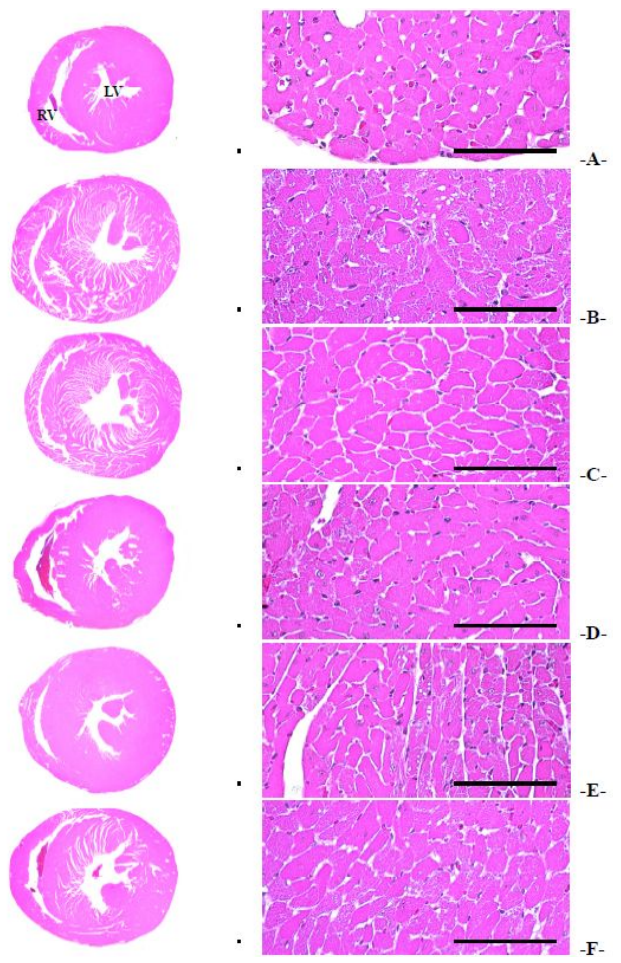

Fig. 4. The representative general histological images of heart, taken from sham or TAC operated mice.

A : sham control, B : TAC control, C : resveratrol, D : SR 500, E : SR 250, F : SR 125.

All Hematoxylin-Eosin stain. Scale bars $=100 \mu \mathrm{M}$ SR : Scrophulariae Radix aqueous extracts, TAC : transverse aortic constriction, RV : right ventricle, LV : left ventricle

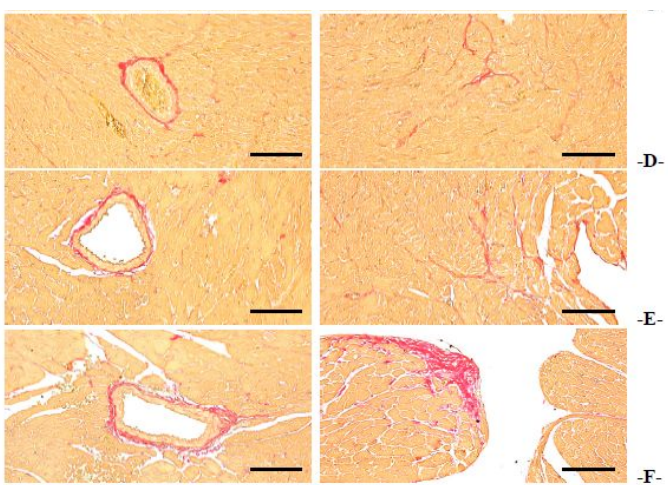

Fig. 5. The representative collagen stained histological images of heart left ventricle, taken from sham or TAC operated mice.

A : sham control, B : TAC control, C : resveratrol, D : SR 500, E : SR 250, F : SR 125. All Sirius red stain. Scale bars : $100 \mu \mathrm{M}$ SR : Scrophulariae Radix aqueous extracts, $\mathrm{TAC}$ : transverse aortic constriction

\section{Discussion}

One of the most important risk factors for the onset of $\mathrm{HF}$ is chronic hypertension and imposes long-term PO on the heart ${ }^{14}$. PO leads to compensated cardiac hypertrophy in the early stages, which can lead to HF due to irreversible dysfunction at the later stages ${ }^{15}$.

Oxidative stress causes cardiovascular events such as heart failure and atherosclerosis, ischemic heart disease, and cardiac cell death ${ }^{16-18}$. To prevent oxidative stress, mammalian have a elaborate antioxidant mechanisms, including SOD and CAT, and other nonenzymatic antioxidants including $\mathrm{GSH}^{19}$.

Antioxidants exert cytoprotective effects by weakening the catalysis of ROS formation by directly eliminating ROS or its precursors and binding to metal ions ${ }^{19}$. Various toxic substances in lipid peroxidation destroy surrounding tissues ${ }^{20.21}$, 
and the oxidative stress is also important inducer of heart damage ${ }^{15,19,22}$.

GSH is a representative endogenous antioxidant and maintains a low level of ROS and maintains a specific cell concentration, thereby preventing tissue damage and being recognized as a protective antioxidant factor of the tissue ${ }^{23}$. SOD is one of the antioxidant enzymes that plays an important role in enzyme defense mechanisms in the heart ${ }^{15,22.24}$, and CAT is a enzyme catalyzes the conversion of $\mathrm{H}_{2} \mathrm{O}_{2}$ to $\mathrm{H}_{2} \mathrm{O}^{25}$.

Thus, inhibition of lipid peroxidation and ROS increase is important in terms of assisting in protecting cardiac damage in $\mathrm{HF}$ by increasing GSH content, SOD and CAT activity in damaged cerebral tissues ${ }^{15,19,22}$.

SR is traditionally used in many prescriptions for treating cardiovascular diseases ${ }^{2.13,26,27}$ with additional anti-angiogenesis, anti-inflammatory and antimicrobial activities ${ }^{8-10}$.

In this study, the cardioprotective effects of SR was observed on the PO-induced HF by TAC in C57BL/6 mice through possible antioxidant effects. SR doses were selected according to previous animals studies ${ }^{28}$. A strong cardioprotective effect due to the antioxidant effect on the TAC mice model was compared to the already proven effect of resveratrol at a dose of $10 \mathrm{mg} / \mathrm{kg}^{2}$, as reference. SR 500, 250, $125 \mathrm{mg} / \mathrm{kg}$ and resveratrol 10 $\mathrm{mg} / \mathrm{kg}$ were administered orally once a day for 14days, and mortality, body and heart weights, histopathology of heart, antioxidant defense system of the heart was analyzed.

According to the previous TAC experiments. ${ }^{4.19}$, the survival probability of animals in TAC surgery reached $60-80 \%$, and also in the present study, $62.5 \%$ in TAC control were detected. However, as a result of oral treatment, increases of survivabilities were demonstrated by SR 500, 250, $125 \mathrm{mg} / \mathrm{kg}$ as 100.0, 87.5 and $75.0 \%$ dose-dependently and by resveratrol $10 \mathrm{mg} / \mathrm{kg}$ as $75.0 \%$. In particular, SR $125 \mathrm{mg} / \mathrm{kg}$ showed a similar increase in survival compared to resveratrol $10 \mathrm{mg} / \mathrm{kg}$. Therefore, survival was seen as direct evidence that PO-induced HF could be inhibited in TAC mice compared to survival of resveratrol at $10 \mathrm{mg} / \mathrm{kg}$ at a dose level of at least $125 \mathrm{mg} / \mathrm{kg}$.

There was no significant change in body weight when compared to the sham control in the TAC control. In addition, resveratrol $10 \mathrm{mg} / \mathrm{kg}$, SR 500 , 250, and $125 \mathrm{mg} / \mathrm{kg}$ did not affect body weight compared to sham and TAC control mice over all experimental periods.

A significant increase in left ventricular heart weight, hypertrophy, solute and local fibrosis histologic changes was markedly and dose-dependently suppressed by 14 consecutive oral treatments of SR 500, 250 and $125 \mathrm{mg} / \mathrm{kg}$, respectively.

In particular, SR $125 \mathrm{mg} / \mathrm{kg}$ significantly affected heart weight and histopathological changes compared to that of resveratrol $10 \mathrm{mg} / \mathrm{kg}$.

MDA contents of the heart observed by lipid peroxidation, and GSH, SOD and CAT activities were observed as antioxidant effect ${ }^{1924}$. Currently SR treatment significantly inhibits cardiac lipid peroxidation dose-dependently and also increases SOD and CAT activity and GSH levels compared to TAC control. In particular, the total effect of SR $125 \mathrm{mg} / \mathrm{kg}$ is comparable to resveratrol 10 $\mathrm{mg} / \mathrm{kg}$.

Thus, SR is regarded as clear and direct evidence that it favorably alleviates PO-induced $\mathrm{HF}$ by TAC comparable to the level of resveratrol 10 $\mathrm{mg} / \mathrm{kg}$ at a dose level of $125 \mathrm{mg} / \mathrm{kg}$. 
There were studies that confirmed the cardioprotective effect in mice by the same experimental method ${ }^{29-31}$. Both Schisandrae Fructus $(\mathrm{SF})^{29}$ and Lonicerae Flos $(\mathrm{LF})^{31}$ study showed an effect comparable to resveratrol $10 \mathrm{mg} / \mathrm{kg}$ at a dose of $250 \mathrm{mg} / \mathrm{kg}$, and Salvia Miltiorrhiza Radix (SMR) ${ }^{30}$ study was similar to the effect of resveratrol $10 \mathrm{mg} / \mathrm{kg}$ at a dose of $125 \mathrm{mg} / \mathrm{kg}$. That is, SR of this study was effective at a dose of $125 \mathrm{mg} / \mathrm{kg}$, which is low dose than SF and LF, and showed a similar effect, although not significantly superior to SMR.

Although SR has a remarkable cardioprotective effect in comparison with the above series of study, clinical and experimental reports have only published on anti-inflammatory ${ }^{8}$, antimicrobial ${ }^{9}$ activities, and $^{-}$ anti-angiogenesis ${ }^{10}$. In addition, the study that SR has a cardioprotective effect is the only paper on the ventricular remodeling rats model induced by coronary artery ligation ${ }^{1213}$.

Therefore, screening of biologically active compounds in SR should be performed in the future through more detailed mechanism studies.

\section{Conclusion}

This study examined the cardioprotective effect of $\mathrm{SR}$ on PO-induced HF by TAC in C57BL/6 mice through antioxidant effects. The mortality, changes in body and heart weights, antioxidant defense system and histopathology of the heart was observed. The results suggest that oral administration of SR advantageously alleviates the PO-induced HF by TAC through enhancing the heart antioxidant defense system. The overall effect of SR $125 \mathrm{mg} / \mathrm{kg}$ is similar to the effect of resveratrol $10 \mathrm{mg} / \mathrm{kg}$. More detailed mechanism studies should be conducted through the screening of biologically active compounds of SR in the future.

\section{References}

1. Juric D, Wojciechowski P, Das DK, Netticadan T. Prevention of concentric hypertrophy and diastolic impairment in aortic-banded rats treated with resveratrol. Am J Physiol Heart Circ Physiol 2007;292(5):H2138-43.

2. Gupta PK, DiPette DJ, Supowit SC. Protective effect of resveratrol against pressure overloadinduced heart failure. Food Sci Nutr 2014;2(3) :218-29.

3. Movahed A, Yu L, Thandapilly SJ, Louis XL, Netticadan T. Resveratrol protects adult cardiomyocytes against oxidative stress mediated cell injury. Arch Biochem Biophys 2012;527(2):74-80.

4. Qi J, Liu Q, Gong K, Yu J, Wang L, Guo L, et al. Apocynum tablet protects against cardiac hypertrophy via inhibiting AKT and ERK1/2 phosphorylation after pressure overload. Evid Based Complement Alternat Med 2014;2014:769515.

5. Wojciechowski P, Juric D, Louis XL, Thandapilly SJ, Yu L, Taylor C, et al. Resveratrol arrests and regresses the development of pressure overloadbut not volume overload-induced cardiac hypertrophy in rats. $J$ Nutr 2010;140(5):962-8.

6. Thandapilly SJ, Wojciechowski P, Behbahani J, Louis XL, Yu L, Juric D, et al. Resveratrol prevents the development of pathological cardiac hypertrophy and contractile dysfunction in the SHR without lowering blood pressure. Am J Hypertens 2010:23(2):192-6.

7. Xie XY, Xia CS. Advances in studies on chemical constituents and pharmacological activities of Scrophularia ningpoensis Hemsl. Asia Pac 
Tradit Med 2010:5:121-5.

8. Díaz AM, Abad MJ, Fernández L, Silván AM, De Santos J, Bermejo P. Phenylpropanoid glycosides from Scrophularia scorodonia: in vitro antiinflammatory activity. Life Sci 2004;74(20):2515-26.

9. Li J, Huang X, Du X, Sun W, Zhang Y. Study of chemical composition and antimicrobial activity of leaves and roots of Scrophularia ningpoensis. Nat Prod Res 2009:23(8):775-80.

10. Wang S, Zheng Z, Weng Y, Yu Y, Zhang D, Fan W, et al. Angiogenesis and anti-angiogenesis activity of Chinese medicinal herbal extracts. Life Sci 2004;74(20):2467-78.

11. Xu FQ, Xu XD, Chen SL. Progress in chemical constituents and bioactivities of Scrophularia ningpoensis. Mod Chin Med 2013;126(15):752-9.

12. Gu WL, Chen CX, Wu Q, Lü J, Liu Y, Zhang SJ. Effects of Chinese herb medicine Radix Scrophulariae on ventricular remodeling. Pharmazie 2010:65(10): 770-5.

13. Huang XY, Chen CX, Zhang XM, Liu Y, Wu XM, Li YM. Effects of ethanolic extract from Radix Scrophulariae on ventricular remodeling in rats. Phytomedicine 2012;19(3-4):193-205.

14. Levy D, Larson MG, Vasan RS, Kannel WB, Ho KK. The progression from hypertension to congestive heart failure. JAMA 1996:275(20) :1557-62.

15. Dai DF, Hsieh EJ, Liu Y, Chen T, Beyer RP, Chin MT, et al. Mitochondrial proteome remodelling in pressure overload-induced heart failure: the role of mitochondrial oxidative stress. Cardiovasc Res 2012;93(1):79-88.

16. Griendling KK, FitzGerald GA. Oxidative stress and cardiovascular injury: part II: animal and human studies. Circulation 2003a;108(17) :2034-40.

17. Griendling KK, FitzGerald GA. Oxidative stress and cardiovascular injury: Part I: basic mechanisms and in vivo monitoring of ROS. Circulation 2003b;108(16) :1912-6.

18. Crow MT, Mani K, Nam YJ, Kitsis RN. The mitochondrial death pathway and cardiac myocyte apoptosis. Circ Res 2004;95(10):957-70.

19. van Empel VP, Bertrand AT, van Oort RJ, van der Nagel R, Engelen M, van Rijen HV, et al. EUK-8, a superoxide dismutase and catalase mimetic, reduces cardiac oxidative stress and ameliorates pressure overload-induced heart failure in the harlequin mouse mutant. $J A m$ Coll Cardiol 2006;48(4):824-32.

20. Comporti M. Lipid peroxidation and cellular damage in toxic liver injury. Lab Invest 1985; 53(6) :599-623.

21. Mansoorali KP, Prakash T, Kotresha D, Prabhu K, Rama Rao N. Cerebroprotective effect of Eclipta alba against global model of cerebral ischemia induced oxidative stress in rats. Phytomedicine 2012;19(12):1108-16.

22. Koga K, Kenessey A, Ojamaa K. Macrophage migration inhibitory factor antagonizes pressure overload-induced cardiac hypertrophy. Am J Physiol Heart Circ Physiol 2013:304(2):H282-93.

23. Odabasoglu F, Cakir A, Suleyman H, Aslan A, Bayir Y, Halici M, et al. Gastroprotective and antioxidant effects of usnic acid on indomethacin -induced gastric ulcer in rats. $J$ Ethnopharmacol 2006;103(1) :59-65.

24. Bento DB, de Souza B, Steckert AV, Dias RO, Leffa DD, Moreno SE, et al. Oxidative stress in mice treated with antileishmanial meglumine antimoniate. Res Vet Sci 2013;95(3):1134-41.

25. Cheeseman KH, Slater TF. An introduction to free radical biochemistry. Br Med Bull 1993; 49(3) :481-93. 
26. Wagner H, Bauer R, Merlchart D, Xiao PG, Staudinger A. Chromatographic fingerprint analysis of herbal medicines (TLC and HPLC of Chinese Drugs). vol 2. Wien: Springer; 2011, p. $427-37$.

27. Zhang CC, Gu WL, Wu XM, Li YM, Chen CX, Huang XY. Active components from Radix Scrophulariae inhibits the ventricular remodeling induced by hypertension in rats. Springerplus 2016:5:358.

28. Kim HS, Park SI, Choi SH, Song CH, Park SJ, Shin YK, et al. Single oral dose toxicity test of blue honeysuckle concentrate in mice. Toxicol Res 2015:31(1):61-8.
29. Lee JS. Schisandrae Fructus administration ameliorates the pressure overload-induced heart failure in mice. Graduate School Daegu Haany University 2014.

30. Kim SW. Cardioprotective effects of Salviae Milt iorrhiza radix on the pressure overloaded heart failure model by transverse aortic constriction-induced mice. Graduate School Daegu Haany University 2015.

31. Shin JW. Protective effect of Lonicerae Flos aqueous extracts against pressure overload-induced heart failure model in mice. Daegu Haany University 2016. 